It was felt that he was suffering from an anxiety state in relation to these difficulties, and he was treated as an outpatient.

Psychological Testing.-I.Q. W.A.I.S. verbal 68, performance 94. Full scale 78. Reading age 6 years (High subtest scatter. Those least dependent on verbal skills having the highest score.)

Progress.-He agreed to individual remedial help at the hospital at which he worked, and this was being continued.

\section{Treatment}

Treatment for dyslexia is difficult. Longstanding aversion to scholastic approaches is obvious, and motivation is low (Gann, 1945; Creak, 1930). Offers of help in a special reading clinic were too threatening as this reminded the patient of school and previous failures. Individual tuition would seem the only solution, but even this was rejected by most patients in this study. Three patients, however, did accept individual help. In case 2 the patient for whom only the offer of private tuition proved acceptable has made impressive progress. In this particular case there was strong motivation to overcome the dyslexia. Two patients (Cases 5 and 7) also accepted, and were oiven, individual remedial classes but stopped after a very short time. The others refused outright. For these psychiatric help was directed towards getting them to accept their disability and talk about it openly. They remained, however, highly vulnerable.

\section{Discussion}

In all these patients the dyslexia was not elicited by the general practitioners or physicians from whom all referrals came. In some cases it was not discovered at the initial psychiatric interview and became apparent subsequently, often only after further information had been obtained from relatives. It is thus highly likely that in many similar patients the dyslexia and associated difficulties remain undetected.

All the patients in this group had received conventional schooling, and there were no neurological or other physical abnormalities elicited. They showed certain personality characteristics. They were all extremely sensitive about their disabilities, and had over the years gone to great lengths to hide them from their families, friends, and workmates, avoiding situations where the disability would become apparent.

In the family, marital friction was commonly found in these patients, who, though highly dependent on their wives, resented this bitterly. In case 2 it was in fact the non-dyslexic wife who was referred for help. When the children in cases 1 , 4 , and 5 went to school and started to read this had apparently acted as the precipitant in their fathers' breakdowns.

Their existence in the community before referral had been a precarious one and specific stresses-for example, of job pro- motion demanding paperwork-had thus been effective in causing the patients disproportionate upset. A pattern of inferiority and mild paranoid reactions to others emergedsimilar to that described by McCready (1926) and Orton (1937) in children.

All the dyslexic patients reported on above were men. This is presumably because there are greater social pressures on men than on women. It must also be less humiliating for a wife to be unable to read and be dependent on her husband to do this for her, than vice versa. The various childhood series studied show an approximate 4 to 1 male: female ratio (Critchley, 1970).

The results of intelligence testing are likely to underestimate the patients' true ability on two counts. Firstly, poor results on verbal tests due to the dyslexia, and, secondly, poor performance in tests, this being the type of situation these patients had previously assiduously avoided. In some patients the actual reading and spelling ages obtained on testing were not in themselves markedly low (case 4), and some had previously attempted to overcome the difficulty themselves, but hesitancy and lack of fluency were pronounced, and reading still caused the patient major concern and embarrassment.

A survey by the National Association of Remedial Education (Daily Telegraph, 1971) concerning 400 illiterates, due to be published shortly, produced the following statements: A father: "I want to be able to keep pace with my 5-year-old daughter." A teenaged girl: "Learning to read will help me to get a boyfriend." A workman: "I can be a foreman as soon as I can read." Perhaps the most significant reply was "I want to be a normal person." The association stresses the very small proportion of adult illiterates that go to classes as a result of tremendous feelings of guilt and embarrassment.

We should like to thank Mr. M. Preston and Mr. J. Peel for the psychological testing, and for arranging the remedial programmes mentioned above.

\section{References}

Brown, R. I., and Bookbinder, G. E. (1966). Audio-visual Programmed Reading Material. Privately printed, Bristol.

Creak, M. (1930). Archives of Disease in Childhood, 2, 143.

Critchley, M. (1970). The Dyslexic Child. London, Heinemann.

Daily Telegraph, 1971, 25 August, p. 2.

Gann, E. (1945). Reading Difficulty and Personality Organisation. New York, Kings Crown Press.

Ingram, T. T. S. (1964). Practitioner, 192, 503.

Ingram, 1. T. S. (1964). Practitioner, 192, 003.

McCready, E. B. (1926). American fournal of Psychiatry, 6, 267. London, Chapman and Hall.

World Federation of Neurology (1968). Research Group on Developmental Dyslexia.

\title{
Genital Yeast Infections
}

\section{J. D. ORIEL， BETTY M. PARTRIDGE， MAIRE J. DENNY， J. C. COLEMAN}

British Medical fournal, 1972, 4, 761-764

\section{Summary}

Genital yeast infection was studied in 533 women seen in a department of venereology. Yeasts were recovered in

West London Hospital, Charing Cross Hospital Group, London S.W.6

J. D. ORIEL, M.D., Consultant Venereologist. (Present address: Department of Venereology, University College Hospital, London W.C.1)

Charing Cross Hospital Medical School, London W.C.2

BETTY M. PARTRIDGE, PH.D., Senior Lecturer in Mycology

MAIRE J. DENNY, A.I.M.L.T., Senior Technician in Mycology

J. C. COLLMAN, M.R.C.PATH., Senior Lecturer in Microbiology culture from 138 patients ( $26 \%$ of the total). Candida albicans accounted for $112(81 \%)$ of the isolates and Torulopsis glabrata for $22(16 \%)$; other yeasts were uncommon. There was no evidence that the presence of yeasts was related to age. $32 \%$ of the women who were taking an oral contraceptive harboured yeasts, compared with $18 \%$ of those who were not.

The symptoms and signs of the women with yeast infections were compared with those with vaginal trichomoniasis and those with no evidence of genital infection. It seems that a clinical diagnosis of vaginal mycosis cannot be made with accuracy and that positive identification of yeasts is necessary; for this, cultural methods are the most satisfactory. 
Finally, the sexual infectivity of vaginal mycosis was assessed. Five out of 48 men who were sexual contacts of women with vaginal yeast infection were found to have mycotic balanoposthitis.

\section{Introduction}

Yeasts, particularly Candida albicans, are often present on the human genitalia. They may occur as apparent commensals in the vagina and to a less extent on the penis but may also cause both vulvovaginitis and balanoposthitis. The reasons for the appearance of clinical symptoms and signs of yeast infection as opposed to carriage of the organisms as commensals are often obscure.

Among the factors which provoke an increase in the occurrence of yeasts are pregnancy, diabetes mellitus, and the use of broad-spectrum antibiotics and corticosteroids. The relation between vaginal mycosis and oral contraception has been the subject of some controversy. Earlier reports (Yaffee and Grots, 1965; Catterall, 1966; Porter and Lyle, 1966; Walsh et al., 1968) indicated that there was a high incidence of clinical candidiasis in women taking oral contraceptives, and Diddle et al. (1969) observed that clinical candidiasis increased with the duration of oral contraceptive medication. Other workers, however, did not agree with these opinions (Morris and Morris, 1969; Rohatiner and Grimble, 1970).

The importance of yeasts as actual or potential pathogens of the female genital tract has led to many studies of their distribution in various population groups. Many have been undertaken in gynaecological departments, where patients presumably have symptoms and are therefore to some extent selected (Timonen et al., 1966; Diddle et al., 1969). Other investigations have been carried out in antenatal clinics (Hurley et al., 1972), in family planning clinics (Rohatiner and Grimble, 1970), and in general practice (Anyon et al., 1971). The mycological methods used for diagnosis are variable and not always complete (Diddle et al., 1969).

Few studies have been undertaken in departments of venereology (Rohatiner and Grimble, 1970). The patients who visit these departments comprise a young, sexually active group, many of whom are taking oral contraceptives, and they have not usually had any treatment before they attend. The objectives of the present study were to investigate the natural history of yeast infections as seen in a large department of venereology, with particular reference to the types of yeasts isolated and their relation to symptomatology and clinical syndromes. The effect of oral contraceptives on the vaginal yeast flora was studied and the infectivity to male sexual contacts was investigated. Finally, diagnostic methods were reviewed and the value of positive yeast identification in clinical management was assessed.

\section{Subjects and Methods}

The patients were seen in the department of venereology at the West London Hospital in May and June 1971. Women who visit the department do not necessarily do so because they have symptoms. Often they come because a sexual contact has a genital infection or simply because they are worried about venereal disease. Women were included in the project if they were attending the department for the first time and were excluded if they were pregnant or if they had taken any antibiotics or received any local treatment during the preceding four weeks.

Clinical Examination.-After the history had been taken the patients were examined in the lithotomy position. The external genitalia were inspected and the vagina and cervix examined after a Cusco speculum had been inserted. Specimens were collected as follows. (1) Urethral and cervical material was spread on glass slides and culture plates for the gonococcus were inoculated (see below). (2) Vaginal material was spread on a slide and a further specimen was suspended in a drop of saline and covered with a coverslip; culture media for Trichomonas vaginalis and for yeast identification were also inoculated.

Microbiological Examination.-Wet preparations were examined immediately under dark-ground illumination for $T r$. vaginalis. Urethral, cervical, and vaginal smears were stained by Gram's method and examined for Neisseria gonorrhoeae, yeast cells, and hyphae. Selective culture plates (Oxoid) were used for the isolation of $N$. gonorrhoeae; Feinberg-Whittington medium (supplied by Southern Group Laboratories) was used for the culture of Tr. vaginalis, and dextrose-peptone agar (Sabouraud's medium) for primary yeast isolation. All cultures were examined in the laboratory. Identification of yeast isolates was based on a series of morphological and biochemical tests, including growth in serum for germ tubes, cornmeal agar cultures for mycelium formation and chlamydospore production, growth and colour change on triphenyltetrazolium chloride medium (Denny and Partridge, 1968), and, when required, sugar fermentation reactions according to Lodder (1970).

Recording of Results.-Clinically vulvovaginitis was defined as vulval or vaginal erythema with or without vulval scaling, oedema, or excoriation. Vaginal plaques were raised white or yellow curdy patches, often adherent to an inflamed vaginal wall. Diagnostic categories were made according to the following criteria. Gonorrhoea: characteristic intracellular Gram-negative diplococci on smear or positive cultures; trichomoniasis: characteristic motile organisms on the wet slide or positive culture; non-specific genital infection: contacts of men with non-specific urethritis; yeast infection (mycosis): isolation of yeasts on culture.

\section{Results}

Altogether 533 patients were studied during this investigation. The diagnostic categories are shown in Table I.

TABLE I-Diagnostic Categories of the 533 Patients

Mycosis only

Mycosis + gonorrhoea

Mycosis + gonorrhoea +

Mycosis + trichomoniasis

Mycosis + non-specific genital infection

Gonorrhoea

Trichomoniasis

Non-specific genital infection

Non-specific genital infection
Others + no appreciable disease

The occurrence of different yeasts is shown in Table II. C. albicans accounted for $112(81 \%)$ of the total isolates and Torulopsis glabrata for $22(16 \%)$. Other yeasts were uncommon. 


\section{AGE INCIDENCE}

The age distribution of patients with yeast infections is shown in the Chart. Most positive isolates were found at the age of 20. When the results are expressed as a proportion of each age group, however, it is seen that in these patients there was no evidence that the presence of yeasts was related to age.

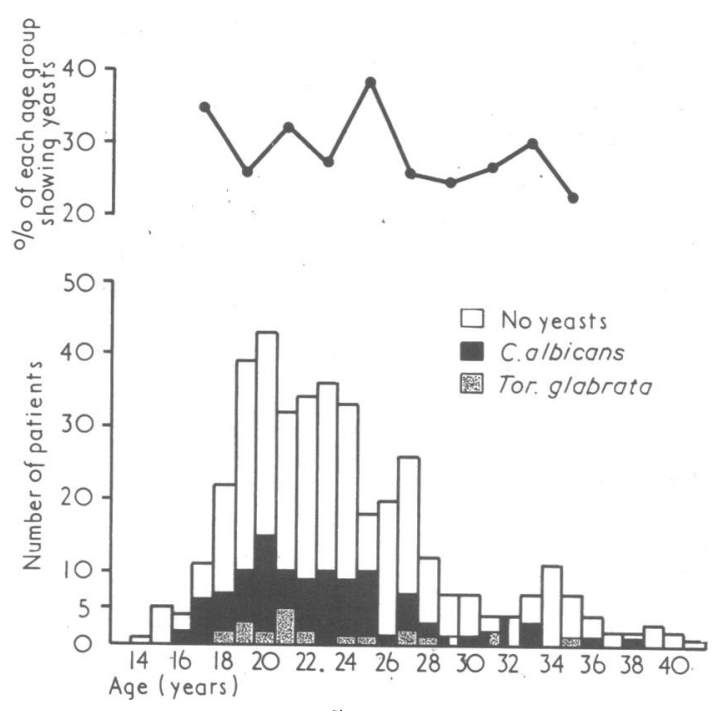

Distribution of yeast isolates according to age.

\section{EFFECT OF ORAL CONTRACEPTIVES}

Of the 241 patients $\left(45_{\%}^{\circ}\right)$ taking an oral contraceptive at the time of examination $32 \%$ harboured yeasts; the comparable figure for those not on oral contraceptives was $18 \%$ (Table III).

TABLE III-Use of Oral Contraceptives and Presence of Vaginal Yeast Flora

\begin{tabular}{cc|c|c|c|c|c}
\hline & & \begin{tabular}{c} 
Propor- \\
\cline { 5 - 6 }
\end{tabular} & $\begin{array}{c}\text { Po. of } \\
\text { tion of } \\
\text { Patients } \\
\text { with yeasts }\end{array}$ & $\begin{array}{c}\text { Candida } \\
\text { albicans }\end{array}$ & $\begin{array}{c}\text { Candida } \\
\text { para- } \\
\text { psilosis }\end{array}$ & $\begin{array}{c}\text { Turolopsis } \\
\text { glabrata }\end{array}$ \\
\hline $\begin{array}{c}\text { Taking oral } \\
\text { contraceptives }\end{array}$ & $\ldots$ & 241 & $32 \%$ & 70 & 0 & 14 \\
$\begin{array}{c}\text { Not taking } \\
\text { contraceptives }\end{array}$ & $\ldots$ & 292 & $18 \%$ & 42 & 1 & 9 \\
\hline All patients & $\ldots$ & 533 & $26 \%$ & 112 & 1 & 23 \\
\hline
\end{tabular}

\section{CLINICAL SYNDROMES}

The characteristic symptoms of a vaginal mycosis are pruritus with or without a vaginal discharge, and the characteristic signs are vulvovaginitis (as defined above) with or without the presence of vaginal plaques. The occurrence of these symptoms and signs were investigated in three groups of patients-those from whom yeasts were isolated as the only pathogen (90), those with only a $T r$. vaginalis infestation (60), and those from whom no pathogenic micro-organisms were recovered (170). The results are shown in Table IV.

Pruritus with or without discharge was complained of by half of the women harbouring C. albicans; however, $23 \%$ of the women with trichomoniasis and $19 \%$ of those with negative tests also had these symptoms. Vaginal discharge as the only symptom was not particularly characteristic of vaginal mycosis; $30 \%$ of those with $C$. albicans and $38 \%$ of those with negative results complained of it. As might be expected vaginal discharge was more common in women with trichomoniasis, in $50 \%$ of whom it was the presenting symptom. It is of interest that about the same proportion of patients had asymptomatic candidiasis
TABLE IV-Symptoms and Signs in Vaginal Infections

\begin{tabular}{|c|c|c|c|c|c|c|c|c|}
\hline & \multicolumn{8}{|c|}{ Patients with: } \\
\hline & \multicolumn{2}{|c|}{$\begin{array}{l}\text { Candida } \\
\text { albicans }\end{array}$} & \multicolumn{2}{|c|}{$\begin{array}{l}\text { Torulopsis } \\
\text { glabrata }\end{array}$} & \multicolumn{2}{|c|}{$\begin{array}{c}\text { Trichomonas } \\
\text { vaginalis }\end{array}$} & \multicolumn{2}{|c|}{$\begin{array}{c}\text { Negative } \\
\text { Tests }\end{array}$} \\
\hline & No. & $\%$ & No. & $\%$ & No. & $\%$ & No. & $\%$ \\
\hline $\begin{array}{l}\text { No symptoms } \\
\text { Pruritus with or } \\
\text { without discharge } \\
\text { Discharge } \quad . \\
\end{array}$ & $\begin{array}{l}16 \\
39 \\
24\end{array}$ & $\begin{array}{l}20 \\
50 \\
30\end{array}$ & $\begin{array}{l}6 \\
3 \\
2\end{array}$ & $\begin{array}{l}55 \\
27 \\
18\end{array}$ & $\begin{array}{l}16 \\
14 \\
30\end{array}$ & $\begin{array}{l}27 \\
23 \\
50\end{array}$ & $\begin{array}{l}73 \\
32 \\
65\end{array}$ & $\begin{array}{l}43 \\
19 \\
38\end{array}$ \\
\hline Total & 79 & 100 & 11 & 100 & 60 & 100 & 170 & 100 \\
\hline $\begin{array}{l}\text { Vulvovaginitis with or } \\
\text { without plaques .. }\end{array}$ & 30 & 38 & 2 & 18 & 8 & 14 & 12 & 7 \\
\hline
\end{tabular}

$(20 \%)$ as had asymptomatic trichomonal infestation $(27 \%)$; on the other hand, $43 \%$ of those with normal flora were symptomfree.

The findings on examination characterized vaginal candidiasis better than the symptomatology; $38 \%$ of the women harbouring C. albicans were found to have vulvovaginitis with or without vaginal plaques, whereas these signs were present in only $14 \%$ of those with trichomoniasis and $7 \%$ of those with normal flora.

Only 11 patients harboured Tor. glabrata in the vagina, compared with 79 patients carrying $C$. albicans as the only pathogen. The number with Tor. glabrata was too small to assess the pathogenic role of this yeast, but more than half of the patients were asymptomatic.

Finally, symptoms of yeast infection were not commoner in those taking oral contraceptives. Of the 90 patients harbouring yeasts only and no other organisms $23 \%$ taking an oral contraceptive had no symptoms, compared with $26 \%$ in the group not taking one of these agents.

\section{INFECTIVITY}

Forty-eight men were seen who were sexual contacts of women harbouring yeasts. Five had clinical and mycological evidence of mycotic balanoposthitis. This represents an infectivity rate of the order of $10 \%$ of sexual contacts.

\section{Discussion}

Of all the pathogens identified in the patients seen in this study yeasts, particularly $C$. albicans, were the commonest. The diagnosis of yeast infections by direct microscopy of clinical material is reliable only if the infection is fairly heavy. In wet preparations it is often impossible to detect yeast cells owing to excessive vaginal debris. Gram-stained films are more satisfactory; yeast cells and frequently hyphae (indicating the presence of $C$. albicans) can be observed. Overall, however, even this is not a reliable method of diagnosis, not only because the type of yeast cannot be identified but also because of its insensitivity. In the present study only half of the patients who yielded yeasts on culture showed organisms on direct microscopy; similar observations were reported by Eddie (1968). In our experience it is often the women with the most florid symptoms and signs who give positive results only on culture, indicating a low concentration of yeasts in the specimens. Furthermore, culture is essential for the identification of any yeast present in clinical material.

In this survey $26 \%$ of the patients were found to be carrying yeasts. C. albicans predominated, constituting $81 \%$ of the yeasts isolated. Tor. glabrata accounted for a further $16 \%$, but other yeasts were uncommon. This distribution is in general agreement with those found by others (Hurley et al., 1972), although some workers have reported, in gynaecological practice, a higher proportion of Tor. glabrata (Timonen et al., 1966; Wilkey, 1967).

The overall incidence of yeasts was nearly doubled in those taking oral contraceptives, irrespective of the type of yeast 
isolated. This was not, however, accompanied by an increase in the symptoms or signs of genital mycotic infection. In this department the proportion of patients taking oral contraceptives has nearly doubled in the past four years, and it may be that a general increase in the use of these agents has led to an increase in the occurrence of yeasts in the female genital tract rather than to any specific effect in the production of symptoms or signs of infection.

In the present series $\mathrm{Tr}$. vaginalis infestation was common, occurring in $18 \%$ of women; this is more than three times the rate reported from an antenatal clinic in the same part of London (Hurley et al., 1972). Tr. vaginalis is sexually transmissible (King and Nicol, 1969), and no doubt the high levels found in the present patients were a reflection of their sexual activity. The ratio of yeast infection to $T r$. vaganilis infestation was $1 \cdot 5: 1$, comparable with the ratio of $2: 1$ reported from another department of venereology in London (Catterall, 1971). Simultaneous infection with yeasts and $T r$. vaginalis is uncommon and was found in only 11 patients; the optimal environmental conditions for the organisms may well be quite different (Müller et al., 1967).

Like $T r$. vaginalis, yeasts are often harboured without symptoms. In the present study $27 \%$ of the patients with $\mathrm{Tr}$. vaginalis and $19 \%$ of the patients with yeasts were asymptomatic. Many factors are recognized which lead to an increase in yeasts in the vaginal microflora (Catterall, 1966), but why some patients develop clinical symptoms and signs of yeast infection while others do not is uncertain. Local reaction to the organisms, possibly of an allergic nature (Holti, 1966), is presumably responsible but its nature is incompletely understood. Of the supposedly characteristic symptoms of yeast infection pruritus was found the most often, in $50 \%$ of these patients; the complaint of vaginal discharge was so commonly made by all patients as not to be helpful in clinical diagnosis. Pruritus, however, was also complained of by $23 \%$ of the patients with trichomoniasis and $19^{\circ} \%$ of those with no evidence of infection. Vulvovaginitis with or without the formation of plaques was certainly a more characteristic sign of yeast infection, being present in $38 \%$ of cases; it was observed in only $14 \%$ of patients with trichomoniasis and $7 \%$ of those with negative tests.

Nevertheless, it must be concluded that a clinical diagnosis of vaginal mycosis cannot be made with accuracy, the supposedly characteristic symptoms and signs being present in other conditions. Only a positive identification of yeasts by cultural methods will enable the clinical situation to be interpreted. This is particularly so in patients where multiple infections are not unusual, as in the present series; one-third of these patients harbouring yeasts had other genital infections as well.

When should vaginal yeast infection be treated ? It is sometimes suggested that patients who are carrying yeasts without symptoms do not require treatment, which should be reserved for those with clinical evidence of infection. It is shown here, however, that clinical assessment of vaginal mycosis presents difficulties, particularly when multiple infections are present. In addition there is no way of predicting which women with asymptomatic yeast infections may later develop a clinical mycosis. Finally, about $10 \%$ of men who have intercourse with women with yeast infection develop balanoposthitis. For these reasons we think that when the diagnosis of yeast infection, based on the positive identification of a pathogenic yeast in the laboratory, has been made the patient should be treated, irrespective of whether symptoms or signs of vaginal mycosis are present. Cultural methods as well as being invaluable for precision in diagnosis can then also be used in assessing the results of such treatment.

We are grateful to Professor H. I. Winner for his advice during this undertaking.

\section{References}

Anyon, C. P., Desmond, F. B., and Eastcott, D. F. (1971). New Zealand Medical fournal, 73, 9 .

Catterall, R. D. (1966). Lancet, 2, 830

Catterall, R. D. (1971). British fournal of Venereal Diseases, 47, 45.

Denny, M. J., and Partridge, B. M. (1968). Fournal of Clinical Pathology, $21,383$.

Diddle, A. W., Gardner, W. H., Williamson, P. J., and O'Connor, K. A. (1969). Obstetrics and Gynecology, 34, 373.

Eddie, D. A. S. (1968). Fournal of Medical Microbiology, 1, 153.

Holti, G. (1966). In Symposium of Candida Infections, ed. H. I. Winner and R. Hurley, p. 73. Edinburgh, Livingstone.

Hurley, R., Leask, B. G. S., Faktor, J. A., and de Fonseka, C. I. (1972). urley, R., Leas

In press.
King, A., and Nicol, C. S. (1969). Venereal Diseases, 2nd. edn, p. 245. London, Baillière, Tindall, and Cassell.
Lond

Lodder, J. (1970). The Yeasts: a Taxonomic Study. Amsterdam, North Holland Publishing.

Morris, C. A., and Morris, D. F. (1969). British Medical fournal, 1, 319. Müller, W. A., Holtorff, J., and Blaschke-Hellmessen, R. (1967). Archiv für Hygiene und Bakteriologie, 151, 610.

Porter, P. S., and Lyle, J. S. (1966). Archives of Dermatology, 93, 402.

Rohatiner, J. J., and Grimble, A. (1970). Fournal of Obstetrics and Gynaecology, of the British Commonwealth, 77, 1013.

Timonen, S., Salvo, O. P., Meyer, B., and Haapoja, H. (1966). Acta Obstetricia et Gynecologica Scandinavica, 45, 232.

Walsh, H., Hildebrandt, R. J., and Prystowsky, H. (1968). American fournal of Obstetrics and Gynecology, 101, 991.

Wilkey, I. S. (1967). Australian and New Zealand fournal of Obstetrics and Gynaecology, 7,237.

Yaffee, H. S., and Grots, I. (1965). New England fournal of Medicine, 272, 647 .

\section{Pulmonary Contusion in Children due to Rubber Bullet Injuries}

\section{J. SHAW}

British Medical fournal, 1972, 4, 764-766

\section{Summary}

Three cases of pulmonary contusion occurred in children as a result of injuries from "rubber bullets." Radiological changes were evident soon after the injury, and in one case these persisted for two months. Symptoms disappeared quickly in all three cases.

Royal Belfast Hospital for Sick Children, Belfast Northern Ireland

J. SHAW, M.B., F.R.C.S., Senior Surgical Registrar (Present appointment: Consultant Surgeon, Ulster Hospital, Dundonald, Belfast, Northern Ireland)

\section{Introduction}

A review of all known serious injuries due to the impact of rubber bullets sustained during the present civil unrest in Northern Ireland is to be published elsewhere (Millar, 1972). Three cases of closed chest injury in children are reported here more fully because of the unusual features they present.

The Missile. - The missile is a bullet made of solid rubber measuring $15 \mathrm{~cm}$ by $3.8 \mathrm{~cm}$ and tapering to a blunt point at one end (Fig. 1). It weighs $150 \mathrm{~g}$, and is fired from a riot gun with a muzzle velocity of $116.5 \mathrm{metres} / \mathrm{sec}$. It is used for riot control and is fired into a hostile crowd from a range of more than $30 \mathrm{yd}(27.4 \mathrm{~m})$. It is intended that it should have the wounding characteristics of a baton and inflict no more than painful 